\title{
NORFACE
}

MIGRATION

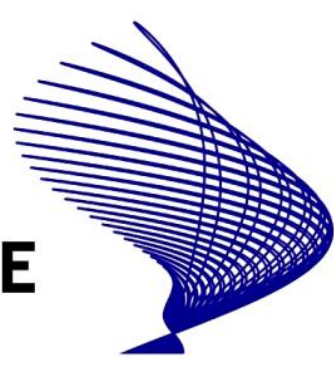

NORFACE MIGRATION Discussion Paper No. 2010-1

\section{The rhetoric of closed borders: quotas, lax enforcement and illegal migration}

Giovanni Facchini and Cecilia Testa 


\title{
The rhetoric of closed borders:
}

\section{quotas, lax enforcement and illegal migration*}

\author{
Giovanni Facchiniłand Cecilia Testa
}

October 21, 2010

\begin{abstract}
In 2008, approximately 12 million immigrants lived illegally in the United States, and large numbers of undocumented foreigners resided also in other advanced destination countries. Hence, attempts at controlling immigration flows seem to often fail. If governments are not enforcing their "official" immigration policy, why do they set such a policy in the first place? The purpose of this paper is to address this apparent puzzle, using a political agency framework. We consider a setting in which there is uncertainty on the supply of migrants, and the policy maker - who faces elections - can be of one of two types. Either he has preferences congruent with the median voter, or he desires a larger number of migrants, because he is interested in the maximization of social welfare or has fallen prey to a pro-immigration lobby. We show that, if the incumbent wants to admit more migrants than the median voter, he might find it optimal to announce a binding quota to be re-elected, and strategically relax its enforcement. The control of migration flows can take place at the border or domestically, and we argue that even if the former is less effective as a policy tool, it might be chosen in equilibrium. Thus, our model illustrates how strategic considerations by elected officials play an important role in explaining both the observed large number of illegal immigrants and lax enforcement.
\end{abstract}

JEL classification: F22, J61.

Keywords: Illegal immigration, Immigration Policy, Political Economy.

${ }^{*}$ Work on this project started while both authors were visiting the RSSS at the Australian National University in Canberra, whose hospitality is gratefully acknowledged. This Paper is produced as part of the CEPR project "Temporary Migration, Integration and the role of Policies" (TEMPO) funded by the NORFACE Research Programme: "Migration in Europe - Social, Economic, Cultural and Policy Dynamics". We would also like to thank seminar participants at the Applied Economics Workshop in Petralia Sottana, III CES-Ifo Workshop on Political Economy, Erasmus University Rotterdam, IZA Conference on Legal and Illicit migration, KU Leuven, Norface CREAM migration Conference in London, Université Catholique de Louvain, Université de Luxembourg, University of Vienna, Warwick University and TOM CEPR workshops in Milan and Venice for very useful comments.

†Erasmus University Rotterdam, Universita' degli Studi di Milano, CEPR, LdA and CES-Ifo; facchini@ese.eur.nl.

${ }^{\ddagger}$ Royal Holloway University of London, Erasmus University Rotterdam and LdA; email: cecilia.testa@rhul.ac.uk. 
"The single most critical issue to protect our nation is the securing of our borders and our ports. (...) At the same time, our government turns a blind eye to the thousands of people who illegally cross our borders. These scenarios exists because corporate America has convinced our leaders that this is one of the best ways to remain competitive"1

\section{Introduction}

Recent estimates for the United States suggest that in January 2008, 12 million individuals were in the country as undocumented aliens, representing approximately four percent of the total number of residents. The sheer size of the problem has made illegal immigration a prominent issue in the political debate, ${ }^{2}$ and it might suggest that the US government is not able to effectively implement its "official" migration policy. Other major immigrant destinations also host large numbers of undocumented foreigners. Recent estimates for a group of them, reported in Table 1 (taken from Fasani 2009), show that also in Italy and Greece (besides the US) well over twenty percent of the total number of foreigners is represented by illegals, and these figures are likely to be a lower bound to the true size of the phenomenon. ${ }^{3}$

At the same time, Hanson and Spilimbergo (2001) - among others - have shown that the extent of migration policy enforcement is negatively correlated with the recent patterns of economic activity in sectors which intensively use illegal immigrants - like agriculture, construction, personal services etc. This evidence suggests that the number of illegal immigrants might be the result of an intentional government policy, which responds to the needs of particular economic interests, rather than of its inability to control the actual flow of foreign workers.

This begs an important question. If governments are not willing to stick to their official policies, why do they set such policies in the first place? The purpose of this paper is to address this apparent puzzle by developing a political economy model in which we show that an elected official might find it optimal to set a binding migration policy, even if he knows that he will not enforce it. In fact, we will show that because of electoral concerns, a government might strategically set an official migration target to please a majority of voters, while relaxing its enforcement to pursue a different objective, such as, for example, maximizing social welfare or pleasing lobbies from sectors who gain from the availability of foreign workers.

In the recent US migration history, lax policy enforcement has been the result of both underfunding and the ineffective use of the resources allocated to enforcement activities. Starting from the late seventies, when the illegal immigration problem has become predominant in the

\footnotetext{
${ }^{1}$ Source: http://loudobbs.tv.cnn.com/category/broken-borders.

${ }^{2}$ See "Obama wins unlikely allies on immigration" The New York Times, July 182010.

${ }^{3}$ Dolado (2007) suggests that in the case of Spain during the nineties, about $98 \%$ of the legal foreign residents in the country had been illegally living in the country at some point.
} 


\begin{tabular}{lccccc}
\hline Country & Stock & Share of foreign pop. & Year & Inflow & Year \\
\hline United States & 12000 & 32.4 & 2008 & 500 & 2008 \\
European Union (15) & & & & 650 & 2001 \\
Austria & 100 & 10.8 & 2003 & 50 & 2001 \\
Italy & 650 & 22.1 & 2008 & 100 & 2001 \\
Germany & 500 & 7.4 & 2005 & 90 & 2001 \\
Greece & 250 & 43.8 & 2007 & 80 & 2001 \\
Spain & 570 & 10.9 & 2008 & 40 & 2001 \\
United Kingdom & 725 & 11.1 & 2007 & 95 & 2001 \\
\hline
\end{tabular}

Table 1: Estimates of stock and flows of illegal immigrants in thousands (Fasani, 2009)

policy debate, several observers have argued that the former has been a major constraint. For instance, the final report of the Select Commission on Immigration and Refugee Policy instituted by the Carter administration strongly supported "... increased funding for the immigration and naturalization service" (Briggs 1982). Even more recently - despite the substantial increase in the budget of the INS, ${ }^{4}$ which has taken place between 1980 and 2004 - the proposal for migration reform put forward by Senators Reid et al. (2010) continues to highlight the need for more investment in migration policy enforcement.

Another important feature of US policy is the disproportionate concentration of resources on border enforcement. As Hanson (2006) points out, between 1980 and 2004 real expenditure in this area has increased over six times, and in 2005 it reached 2.2 billion US dollars. As a result, in 2003, the US authorities devoted more than fifty times more man-hours to "line-watch" (i.e. border) enforcement than to worksite enforcement, a strategy that "...appears ill-suited to curtail unauthorized entry in a country that shares a 2000-mile long land border with a poor neighboor" (Hanson 2006). In other words, the increase in overall funding for policy enforcement seems to have been accompanied by an ineffective use of these resources. More generally, several observers have suggested that the Department of Homeland Security might employ its resources ineffectively for strategic motives (Cornelius et al. 2004).

While intentional lax enforcement may provide an appealing explanation for the observed large numbers of illegal immigrants, the strategic use of inefficient policies is hard to reconcile with the fact that governments should be punished by voters if they behave "badly" behavior. At the same time, to correctly punish politicians, voters must be able to monitor the implementation of migration policy, including its most complex or technical aspects. Since governments typically have better information than the public on the policy making process, elections may sometimes fail to hold them accountable. Hence, to understand why migration enforcement may be slack even

\footnotetext{
${ }^{4}$ The INS is now part of the Department of Homeland Security.
} 
if politicians are subject to the scrutiny of voters, we develop a model which is able to explain the adoption of underinvestment or ineffective enforcement as the result of asymmetric information between the policy maker and the electorate. In our setting, we consider two possible sources of inefficiency. First, the public might not be informed on the budgetary aspects of migration policy, and this may allow the politician to exploit his information advantage to strategically underinvest. Second, voters may not be aware of the characteristics of the enforcement technologies available to the policymaker, and thus they can fall victim of a strategic misallocation of the resources towards a less effective policy instrument.

In our analysis, we consider a two-period setting in which a small country initially faces uncertainty on the potential number of migrants, which can be either high or low, and the probability of the two events is common knowledge. The domestic economy produces one output good, using capital and labor as inputs. Each domestic agent is endowed with one unit of labor, whereas capital ownership is heterogeneous across them. Immigrants are endowed instead only with labor and as a result, domestic residents have heterogeneous preferences towards immigration. In particular, individuals with a higher share of capital prefer a larger number of foreign workers to be admitted, as this will raise the return to capital. Since typical wealth distributions imply that the median voter owns a share of the capital stock in the economy which is below average, he prefers a number of migrants lower than the social surplus maximizing one. Starting from an autarky equilibrium, migration is initially desirable, but due to congestion effects, there exists a finite number of immigrants, which maximizes individual welfare. The actual inflow can be limited by carrying out enforcement activities, the cost of which depends on the difference between the supply of foreign workers and the target chosen by the government. Hence, in our model, the migration policy consists of two elements: a migration target and an enforcement cost.

The actual number of foreign workers entering the country is determined by the politician in power, which can be of one of two types, randomly drawn from the same distribution, which is common knowledge. The first has preferences perfectly aligned with those of the median voter, and we will refer to him as a populist. The second has instead preferences congruent with the average citizen, i.e. he maximizes social surplus, and prefers a larger number of immigrants compared to the populist. We call him benevolent. The type of the politician is unknown to the citizenry. At the beginning of the first period the incumbent chooses the migration policy. At its end, the citizens, having observed only the official migration target and the actual number of foreign workers which have entered the country, use Bayesian updating to revise their beliefs on the type of the incumbent, and decide whether to re-elect him or not. In the second period, the elected politician - with full knowledge of the supply of foreign workers - chooses again the number of immigrants to be admitted and the world ends.

In this set-up, we analyze how re-election concerns might affect migration policy in general, 
and the number of illegal immigrants in particular. In the second period, given that there are no further elections and the government is informed about the supply of foreign workers, politicians choose the migration policy that maximizes their individual welfare, and no illegal immigration arises. The policy choice in the first period is instead more complex, due to the information set-up and the re-election incentives.

Because of the uncertainty on the supply of migrants, the first period migration policy will necessarily be sub-optimal. In particular, if the supply of migrants is high, then the number of foreign workers entering the country will be larger than the target chosen by the government, whereas if it is low, then the government will have over-invested in enforcement. In either case, as long as the migration policy chosen maximizes the expected social surplus, the resulting migration level will be "constrained-efficient" and the (positive) difference between the number of migrants that have entered the country and the migration target represents constrained-efficient illegal immigration.

Elections further complicate matters because, during the first term, the incumbent politician may face an important trade-off. On the one hand, he wants to implement his most preferred policy, on the other he wants to be re-elected. We can show that, while this dilemma does not arise for a politician whose preferences are aligned with those of the median voter, for an official preferring more migrants, choosing his most preferred policy is costly, as it entails an electoral defeat. As a consequence, he tries to exploit his information advantage over the voters to be re-elected, while choosing a policy that is as close as possible to his most preferred one. To achieve this objective he tries to "pool" with his political opponent by setting the same target as the populist, but choose a different enforcement strategy to allow more migrants in the country in a concealed way. For this purpose, he can either underinvest in enforcement compared to what the median voter wishes, or he can allocate the median voter's desired budget to an ineffective enforcement technology. In deciding whether to under-invest or spend more on a less effective technology, the politicians weights the cost and benefits of the two strategies. Underinvesting is better when the state of the world is low, because it generates the same number of migrants while using less resources to carry out enforcement activities. On the other hand, using a larger budget on a less effective technology might be preferable when the state of the world is high because, by spending more on enforcement, the number of migrants admitted may turn out to be closer to the benevolent politician's ideal number. If this potential policy gain is larger than the higher enforcement cost, then an equilibrium with "high but ineffective spending" can arise, whereas strategic under-investment will be chosen otherwise. In both cases, during the first period of office, the benevolent politician adopts a policy which is different from his most preferred one, thus incurring in a utility loss. However, by doing so, he can be re-elected to a second term and choose his most preferred policy under full information, thus achieving his first best. Hence, the 
first period sacrifice might be worth taking, provided that it helps the benevolent politician to be re-elected.

We show that, for the benevolent politician to have a chance of re-election, first of all it is essential that the median voter revises upward his belief that the incumbent is a populist. This is possible only if the supply of migrants is more likely to be high, because only in this case "pooling" is a costly action for the benevolent politician. In fact, if ex-post the potential supply of migrants is large, then the number of illegal immigrants allowed by the "sub-optimal enforcement" is larger than the highest possible level that a populist would choose. Hence, the median voter finds out that the politician is not populist and votes him out. On the other hand, if the number of illegal immigrants is low, the benevolent politician succeeds in convincing the median voter that he is a populist, and that the observed illegal immigration is only due to the imperfect enforcement associated with the uncertainty on the actual migrant supply. As long as the expected gain arising from winning elections is larger than the expected loss from the potential electoral defeat, the benevolent politician decides to choose a suboptimal enforcement. Therefore, our analysis shows that, in the presence of informational asymmetries, electoral considerations may in fact induce politicians to choose an inefficient policy, allowing more migrants to enter illegally than it would be socially desirable. They do so to avoid the electoral punishment brought about by the implementation of a less restrictive target, which would allow a higher number of immigrants to legally enter the country. Thus, our model is able to rationalize both the large number of illegal immigrants observed in many destinations, as well as the systematic adoption of ineffective tools like border enforcement - or the shortage of resources allocated to the control of migration flows.

The remainder of the paper is organized as follows. Section 2 discusses the related literature, whereas section 3 presents the economic environment. Section 4 introduces the political game and section 5 characterizes the policy choice. Section 6 analyzes the choice between border and domestic enforcement and section 7 concludes.

\section{Related Literature}

A substantial literature has developed to study the desirability - from the point of view of the destination country - of immigration in general and, more specifically, of illegal immigration. For a small country, Berry and Soligo (1969) have shown that free migration is the welfare maximizing policy. At the same time, in a world with heterogenous agents, even policies that maximize aggregate welfare might lead to the creation of winners and losers, as has been argued for instance by Borjas (1995). The working of political economy forces, unleashed by the distributional effects of immigration, has resulted in the widespread use of restrictions to the free mobility of labor (Facchini and Mayda 2010) and several papers have developed models which explain the formation 
of policies towards overall migration (Benhabib 1996, Facchini and Willmann 2005 and Epstein and Nitzan 2006). Naturally, if immigration policies are binding, large numbers of potential migrants are not allowed to legally enter the desired destination. Some will be discouraged and decide not to emigrate, but other will try to enter illegally.

Several papers have considered the policies that should be implemented by a welfare maximizing government to limit the inflow of undocumented foreigners. In his pioneering contribution, Ethier (1986) develops a small country model to analyze the effectiveness of different instruments towards this end, focusing on the use of domestic and border enforcement. Bond and Chen (1987) have extended his analysis to a two country setting, allowing also for the possibility of capital mobility. Woodland and Yoshida (2006) have relaxed the assumption that the potential migrants are risk-neutral, to analyze the effects of different attitudes towards risk. Chau (2001) develops instead a model in which the use of immigration amnesties might be optimal in an environment in which border and domestic enforcement suffer from a credibility problem, i.e. they are time inconsistent. These papers provide rich frameworks in which both the decision to migrate and the effects of different policies in the destination countries are considered. On the other hand, they do not explicitly analyze the role of political economy forces in shaping the demand side of illegal immigration, a factor that - as shown by Hanson and Spilimbergo (2001) and Fasani (2009) - can play an important role.

Several papers have developed political economy models of illegal immigration from the point of view of the host country. In an early contribution, Diajic (1987) looks at the level of enforcement which will be chosen by a government as the result of lobbying expenditure in a reduced form model a la Findlay and Wellisz (1982). Similarly, Chau (2003) uses a model with lobbying to study the political process through which border and domestic enforcement are chosen in equilibrium, and under which conditions an amnesty might be introduced. Importantly, in both these frameworks, legal immigration is absent from the model and as a result, the only source of additional labor supply for the destination country's employers is represented by undocumented foreign workers. Hanson and Spilimbergo (2001) and Fasani (2009) develop a similar, simple reduced form lobbying model. Hillmann and Weiss (1999) focus instead on the sectoral dimension of immigration policy. In particular, they show that, even if the median voter in the destination country would prefer no migration at all, if illegal immigration has taken place, and domestic enforcement makes illegal immigrants a "sector specific" input, ex post illegal immigrants will be tolerated and further inflows will be allowed.

In our paper, we also study the political economy forces driving the presence of illegal immigration, but differently from the existing literature, in our model the phenomenon arises endogenously as the result of the migration policy chosen by the government (i.e the combination of an official quota and its enforcement). In our set-up, illegal immigration crucially depends on the migration 
policy because, first, the phenomenon arises whenever the number of foreign workers entering the country is higher than the official quota; and second, the number of illegals depends on the migration quota itself and on the policy implementation efforts undertaken by the government. In particular, illegal immigration is the result of imperfect enforcement, which can be due both to the government's pure lack of information or to its strategic behavior. On the one hand, since the potential supply of foreign workers is uncertain, even a government with preferences aligned with those of the median voter might not be able to limit the inflow of foreign workers to its desired level. On the other, "excessive" illegal immigration can arise as an equilibrium outcome if a politician maximizing social welfare sets a quota to please the median voter, but at the same time strategically relaxes enforcement to obtain his goal.

To show how voter's imperfect information may lead to an inefficient policy, our analysis is carried out within a political agency framework, where the role of re-election incentives can be explicitly analyzed. ${ }^{5}$ In political agency models, the voter (principal) uses elections to both provide incentives and select the best type of politician (agent). However, when information is imperfect, moral hazard and adverse selection arise. In other words, the voter might not be able to discipline the politician and retain what is, from his perspective, the best "type" of elected official. A prominent example of the type of inefficiency that can arise in a political agency framework is illustrated by Coate and Morris (1995). In this paper the authors show that a government concerned about re-election might prefer a "sneaky", inefficient redistributive policy benefitting a lobby over an efficient "open" redistribution scheme which might lead it to lose in the ballot. The spirit of our analysis comes close to Coate and Morris (1995), since also in our model the government might prefer to allow immigrants in the country in a concealed, inefficient fashion, rather than promoting a more open, efficient migration policy. Importantly, our setting differs from theirs, because we consider a framework in which we have both an explicit "policy target" and a costly enforcement activity (Stigler 1970), and the latter is the potential object of strategic manipulations. Thus, our paper is also related to the literature on enforcement of laws and regulations. Research in this tradition (Stigler 1970 and Polinsky and Shavell 2007 among others) focuses on the optimal amount of resources and mechanisms of enforcement, with a particular attention to the working of those agencies responsible for detecting and sanctioning violators, and their potential to misbehave (Mukherjee and Png 1995, Banerjee 1997 and Pagano and Immordino 2010). Alongside this economics literature, which analyzes the behavior of bureaucrats, several scholars in political science have stressed the influence of elected officials on regulatory policy. In particular, according to the so-called "congressional dominance" approach (Weingast and Moran 1983), representatives have several tools at their disposal to control subordinate agencies, one of the most important being the "power of the purse", i.e. the allocation of the budget (Calvert,

\footnotetext{
${ }^{5}$ For an overview of political agency models, see Besley (2006).
} 
Moran, and Weingast 1989). In our analysis we also embrace the view that elected politicians are "powerful", in the sense that they control both the setting of the policy target and its enforcement, and we provide a micro-foundation for the strategic behavior of officials facing rational voters in an asymmetric information setup. Thus, while our focus is on the design and enforcement of migration policy, our analysis has implications for a broad variety of economic environments in which elected officials set both standards and the corresponding enforcement level.

\section{Economic Environment}

Home is an economy which produces one good according to a production function $Y=F(K, E)$, where $K$ is the stock of capital assumed to be exogenously given, and $E$ is total employment. ${ }^{6}$ The economy is populated by a continuum of native individuals indexed by $i \in[0,1]$, and the population size is normalized to unity (i.e. $N=1$ ). Every individual $i$ supplies the same exogenously given amount of labor, and is endowed with a fraction $\lambda_{i}$ of the overall capital stock $K$, with $\int \lambda_{i} d i=1 .{ }^{7}$ Furthermore, let the domestic wage under autarky be larger than the wage prevailing in the rest of the world. Thus, abstracting from relocation costs, foreign workers will find it desirable to migrate into the domestic economy.

Admitting immigrants $I$ leads to welfare gains for Home, which are bounded by the presence of a "congestion" cost $c(I)$, which is a differentiable, increasing and convex function. In the first part of the paper, we focus for simplicity on the situation in which the Home country government has at its disposal a single enforcement technology, and introduce a second instrument in section 6 . To constrain the inflow of immigrants, a cost is sustained which depends on the difference between the supply of foreign workers $\widehat{I}$ and the target $I$ chosen by the government. Let the enforcement cost be $\eta(\widehat{I}-I)$, where $\eta($.$) is an increasing linear function of the chosen migration target I$ (i.e. $\left.\frac{\partial \eta(.)}{\partial I}<0, \frac{\partial^{2} \eta(.)}{\partial I}=0\right)$. Hence, the smaller is the number of migrants $I$ allowed to enter (i.e. the more restrictive the migration policy), the larger is the enforcement cost. Moreover, for any chosen target, a larger supply of migrants has a positive effect on both the total and marginal cost of enforcement (i.e. $\frac{\partial \eta(.)}{\partial \widehat{I}}>0, \frac{\partial^{2} \eta(.)}{\partial \widehat{I} \partial I}>0$ ) implying that the supply of foreign workers $\widehat{I}$ can affect the optimal migration policy. We begin by considering the case where there is only one enforcement technology and illustrate the basic mechanism through which inefficient enforcement may arise in this set-up. In section 6 we extend our discussion to analyze the more complex scenario where the

\footnotetext{
${ }^{6}$ We are assuming that $F^{\prime}(E)>0, F^{\prime \prime}(E)<0$ and $F^{\prime \prime \prime}(E)=0$.

${ }^{7} \mathrm{We}$ are assuming that the distribution of factor ownership is atomless i.e., that every agent only owns a tiny fraction of the total supply of capital. Notice that if we denote with $K_{i}$ the supply of capital by agent $i, \int_{I} K_{i} d i=K$. Since population size is normalized to $1, K$ is also the average supply of capital in the population. Define $\lambda_{i}=\frac{K_{i}}{K}$. Then $E\left(\lambda_{i}\right)=\int_{I} \lambda_{i} d i=1$. In other words, $\lambda_{i}$ can be interpreted as the holding of capital by agent $i$ relative to the population average.
} 
politician can choose between two enforcement technologies, one of which is more effective than the other.

The supply $\widehat{I}$ of foreign migrants is stochastic, and depends on the state of the world $s$, which can be either low $(L)$ or high $(H)$. In particular, let $\hat{I}(L)=\underline{I}$ and $\hat{I}(H)=\bar{I}$, where $\bar{I}>\underline{I}$. The probability that the state of the world is $H(L)$ equals $q(1-q)$. Hence, the utility of a native individual $i$ can be written as follows

$$
u_{i}(E)=\lambda_{i} \pi(E)+w(E)-c(I)-\eta(\widehat{I}(s)-I)
$$

It is easy to show that

Lemma 1 As long as the utility function is concave, the number of immigrants $I_{i}^{*}$ maximizing individual $i$ 's utility is an increasing function of $\lambda_{i}$ and of the the supply of foreign workers $\widehat{I}$.

Proof. The first order condition for the maximization of equation 1 is

$$
u_{i}^{\prime}(I)=-\lambda_{i} L F^{\prime \prime}(I)+F^{\prime \prime}(I)-c^{\prime}+\eta^{\prime}=0
$$

which implicitly defines a function $g\left(I^{*}\left(\lambda_{i}\right), \lambda_{p}\right) \equiv u_{i}^{\prime}(I)=0$. Applying the implicit function theorem, we have that

$$
\frac{d I_{i}^{*}}{d \lambda_{i}}=-\frac{\frac{d g}{d \lambda_{i}}}{\frac{d g}{d I}}
$$

Given that the utility function in equation 1 is concave, $\frac{d g}{d I}<0$. Notice that $\frac{d g}{d \lambda_{i}}=-L f^{\prime \prime}>0$, which implies the result. Moreover, since $\eta^{\prime}$ is increasing in $\widehat{I}$, if the supply of foreign workers increases, for the first order condition to be satisfied, the optimal number of migrants must increase.

The previous lemma implies that individuals with a higher share of capital prefer a larger number of foreign workers to be admitted, as this will raise the return to capital. In particular, since their preferences are single peaked in $I$, domestic residents can be ranked according to their most preferred number of migrants. Hence, there exists a continuum of citizens distributed according to their migration preferences, and we denote by $i=p$ the median of this distribution, and by $\lambda_{p}$ his share of the overall capital stock. Typical wealth distributions imply that $\lambda_{p}<1$, i.e. that the median voter owns a share of the capital stock in the economy which is below the average (Alesina and Rodrik 1994 and Dutt and Mitra 2002).

By aggregating individual preferences, we can write down the social surplus as follows:

$$
S(I)=\pi(E)+w(E)-c(I)-\eta(\widehat{I}(s)-I)
$$

where $\pi(E)$ is the return to immobile capital and $w(E)$ is the wage and $E=N+I$. 
Note that, since the only difference between the utility of an individual $i$ and the social surplus is given by the share of capital $(\lambda=1)$, then lemma 1 also holds if we consider aggregate welfare, which coincides with the utility of the citizen endowed with the average share of capital. As a consequence, because the median voter owns a share of capital below the average $\left(\lambda_{p}<1\right)$, the number migrants maximizing social surplus is necessarily larger than that preferred by the median voter. Furthermore, the number of migrants maximizing domestic welfare is an increasing function of the supply of foreign workers. As a result, since the supply of foreign workers $\widehat{I}$, in the first period, is not observed, then the number of migrants which maximizes the social surplus is given by the weighted average of the quantities maximizing social surplus under the two states of the world, i.e. $I^{*}(H)$ and $I^{*}(L)$, where the weights are given by the probabilities $1-q$ and $q$ respectively. ${ }^{8}$ In other words,

$$
I^{*}=(1-q) I^{*}(L)+q I^{*}(H)
$$

and the corresponding policy enforcement cost is

$$
E(\eta)=(1-q) \eta\left[\underline{I}-I^{*}(L)\right]+q \eta\left[\bar{I}-I^{*}(H)\right]
$$

Notice that ex-post, given the realized supply of foreign workers, this enforcement level will turn out to be sub-optimal in the sense that the actual number of migrants, denoted by $I(s)$, is different from $I^{*}(s)$. To understand this point, consider figure 1, where we have represented the enforcement costs necessary to implement any given level of immigration under the two possible states of the world. If the state of the world is high, to obtain the desired immigration level $I^{\star}(H)$, the government should spend $\eta\left[\bar{I}-I^{*}(H)\right]$. Hence, having spent only

$$
E(\eta) \equiv(1-q) \eta\left[\underline{I}-I^{\star}(L)\right]+q \eta\left[\bar{I}-I^{*}(H)\right]<\eta\left[\bar{I}-I^{*}(H)\right]
$$

the actual number of migrants $I(H)$ entering the country illustrated in figure 1, will be higher than the level $I^{*}$ set by the government. The difference $I(H)-I^{\star}$ represents the number of illegal immigrants. On the other hand, if the state of the world turns out to be low, the government will have overinvested in enforcement, and the number of immigrants actually entering the country $(I(L)$ in figure 1$)$ is lower than the government's target.

\footnotetext{
${ }^{8}$ This follows immediately from the fact that

$$
E[S(I)]=q[\pi(E)+w(E)-c(I)-\eta(\bar{I}-I)]+(1-q)[\pi(E)+w(E)-c(I)-\eta(\underline{I}-I)] .
$$
}




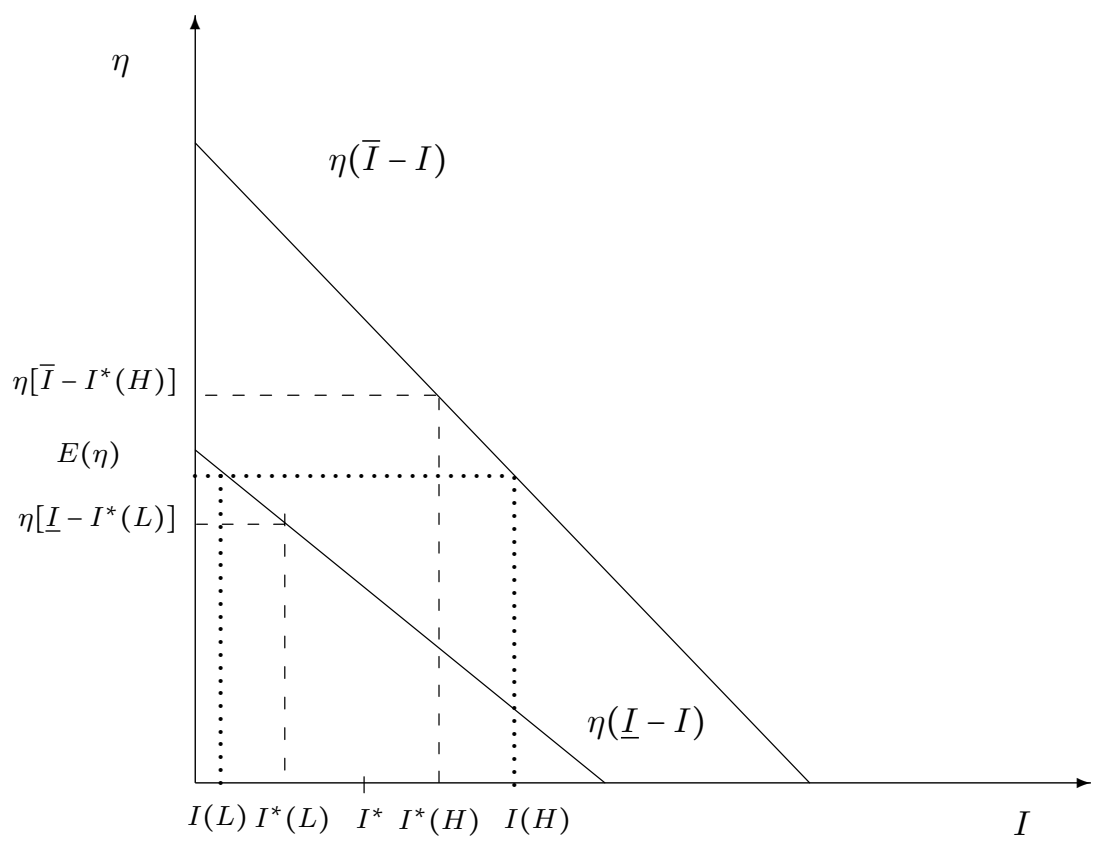

Figure 1: Illegal immigration

\section{The game}

Individuals in this economy live for two periods $t \in\{1,2\}$. Initially, a randomly drawn politician $g$ is appointed to choose in period $t=1$ the migration policy (which constitutes the politician's strategy) prescribing a target $I_{g}$ and enforcement $\eta($.$) for that period. We assume that there are$ only two types of politicians, which are independently drawn from an identical distribution. One type (the "populist", i.e. $g=p$ ) has preferences perfectly aligned with those of the median voter, while the other (the "benevolent", i.e. $g=b$ ) maximizes social surplus, thus prefering a higher level of immigration. The probabilities that the politician is a populist or a benevolent are denoted by $\mu$ and $1-\mu$ respectively.

At the time of the policy choice, neither the politician nor the public observe $\widehat{I}(s)$, but they know its distribution. At the end of the first mandate, having observed the target $I_{g}$ and the actual number of migrants $I(s)$, but neither their supply nor the amount of resources spent on enforcement, voters revise their beliefs on the type of the incumbent according to Bayes rule, and decide whether to reelect him or to replace him with a challenger. The elected politician observes $\widehat{I}(s)$, chooses again the number of immigrants to be admitted in $t=2$, and the world ends. ${ }^{9}$

\footnotetext{
${ }^{9}$ Notice that in the second period, knowing the actual supply of immigrants, the politician will choose his first best policy. This assumption is needed to create an incentive for the official to be reelected and it is more natural, in our framework, than a standard ego-rent from office.
} 
We denote by $P\left[g=p \mid I_{g}, I(s)\right]$ the ex-post probability that the incumbent $(g)$ is a populist $(p)$ when the observed number of migrants is $I(s)$ and the target is $I_{g}$. In carrying out our analysis, we focus on monotonic beliefs which have the following property: ${ }^{10}$ whenever the median voter observes a number of migrants coinciding with his most preferred one, he does not revise downward the probability that the incumbent has his same preferences, and viceversa. In other words, a "good outcome" cannot result in more pessimistic beliefs and a "bad outcome" cannot result in more optimistic ones.

The above structure defines a game of incomplete information between voters and politicians that can be solved by backward induction. A perfect Bayesian equilibrium of this game consists of a migration policy, a voting rule and set of beliefs such that $(a)$ voters' beliefs are generated by Bayesian updating, (b) the voting rule is optimal given the voters' beliefs and the politicians' strategies and $(c)$ the incumbent's strategy is optimal given the voters' beliefs and the opponent's and voters' strategies.

\section{$5 \quad$ Policy choice}

In the second period, because there are no further elections, the incumbent chooses the policy maximizing his own utility. Moreover, because he can observe the supply of foreign workers, he chooses the optimal amount of enforcement (i.e. there is no illegal immigration).

In the first period, the policy choice is more complex because of re-election concerns, and it crucially depends on voters' beliefs. Since beliefs are monotonic, a populist incumbent will always choose the policy preferred by the median voter. In fact, by doing otherwise, he cannot improve his reputation of being a populist, and hence increase his chances of re-election. The same is not true for a benevolent type: by choosing in the first period his most preferred policy - i.e. by playing sincere - he can only decrease his ex-post probability of being considered a populist, whereas by "pooling" with a populist, he may raise it. We focus on three strategies, denoted by $\sigma$, that allow a benevolent incumbent to "pool" with a populist in some state of the world, and we denote by $I_{g}^{\sigma}(s)$ the number of migrants actually entering the country when the politician $g$ chooses strategy $\sigma$ and the state of the world is $s .{ }^{11}$ The first strategy, that we name mimicking $(\sigma=m)$, requires the benevolent politician to choose the same policy - i.e. an immigration target $I_{p}^{*}=(1-q) I_{p}^{*}(L)+q I_{p}^{*}(H)$ and the corresponding level of enforcement - adopted by a populist under any state of the world. The second is an under-investment strategy $(\sigma=u)$, that allows the

\footnotetext{
${ }^{10} \mathrm{As}$ in Coate and Morris (1995), we focus on monotonic beliefs implying that a "good" politician (in our case the populist) will not have incentive to distort the policy. An alternative assumption leading to the same equilibrium outcome would be that the populist does not behave strategically. This avenue is followed for instance by Besley and Smart (2007), who assume that one of the two types of politicians is not strategic.

${ }^{11}$ Notice that our assumption of monotonic belief implies that any other strategy, which would not allow pooling under some state of the world, is dominated.
} 


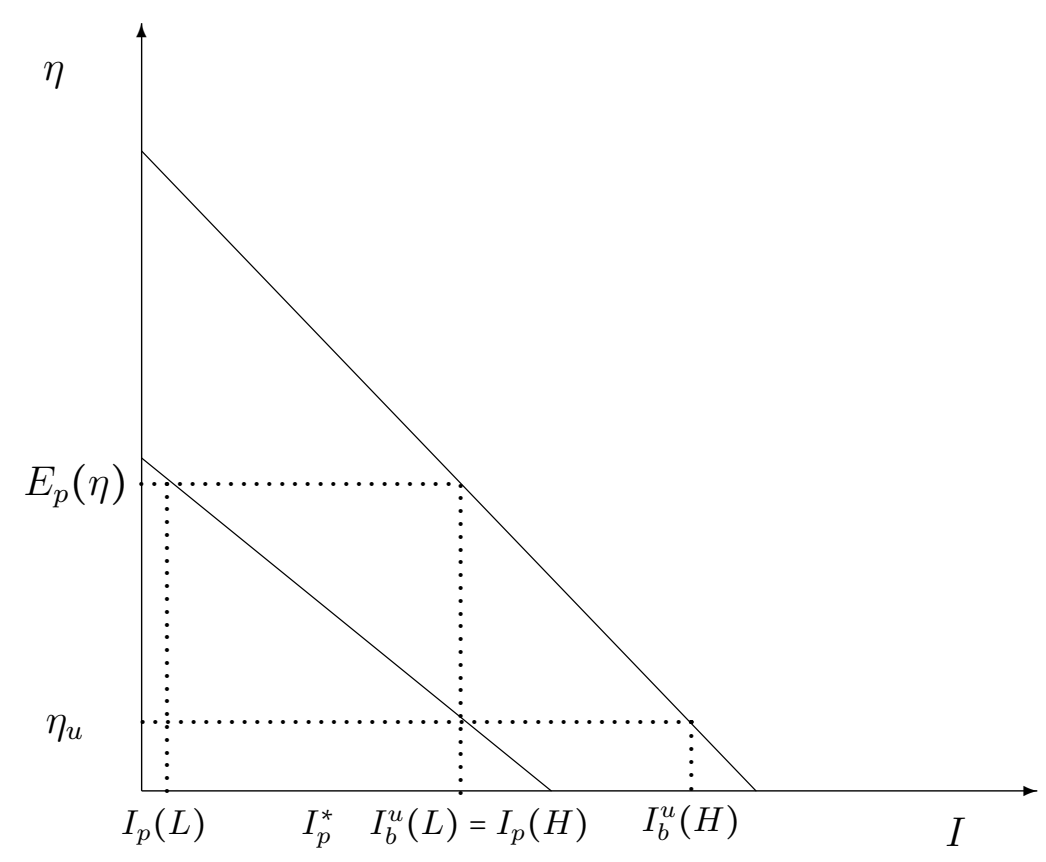

Figure 2: The underinvestment strategy

benevolent politician to "pool" with the populist only if the state of the world is low. To do so, the benevolent official sets the same target $I_{p}^{*}$ as the populist, but strategically under-invests in enforcement choosing an amount $\eta_{u}$ such that, if the state of the world is low, the resulting level of migration is the same one generated by a populist-type under the high state of the world, i.e. $I_{b}^{u}(L)=I_{p}(H)$. However, if the actual supply of immigrants is high, the number of foreign workers entering the country will be higher than both that obtained by maximizing social surplus and the upper-bound obtained by the populist, i.e. $I_{b}^{u}(H)>I_{b}(H)>I_{p}(H)$. With this type of "pooling" strategy the benevolent incumbent tries to exploit his informational advantage on his own type, together with the uncertainty on the state of the world, in order to admit a higher number of migrants and at the same time be re-elected. If the state of the world is low, the incumbent may have a chance to achieve his objective, because he generates the same number of migrants that a populist would admit under the high state of the world. On the other hand, if the state of the world is high, the median voter will uncover the true type of the incumbent, and therefore will not re-elect him. The working of the underinvestment strategy is illustrated in Figure 2.

A similar logic applies to the third strategy we consider, where the benevolent politician overinvests $(\sigma=o)$ to "pool" with the populist only if the state of the world is high. If the state of the world is instead low, the number of migrants entering will be lower than both the lower-bound obtained by the populist, and that obtained by social surplus maximization, i.e. $I_{b}^{o}(L)<I_{p}(L)<$ $I_{b}(L)$. 
We are now ready to describe the voters beliefs' updating process. Given that, based on the available information on the state of the world, a populist politician always chooses the migration level preferred by the median voter, whenever the median voter observes a level of migration different from either $I_{p}(H)$ or $I_{p}(L)$, he concludes that the incumbent is benevolent. On the other hand, denoting by $\gamma_{L}$ the probability that a benevolent incumbent admits a total number $I$ of migrants when the state of the world is low, and by $\gamma_{H}$ the probability that he generates the same number if the state is high, then if voters observe the target $I_{p}^{*}$ and the outcome $I_{p}(H)$, the ex-post probability that the incumbent is a populist can be computed as follows:

$$
P\left[g=p \mid I_{p}^{*}, I_{p}(H)\right]=\frac{\mu q}{\mu q+q(1-\mu) \gamma_{H}+(1-q)(1-\mu) \gamma_{L}}
$$

where $\mu q$ is the probability that $I_{p}(H)$ is generated by a populist, $q(1-\mu) \gamma_{H}$ is the probability that it is generated by a benevolent type mimicking the populist, and $(1-q)(1-\mu) \gamma_{L}$ is the probability that it is generated by a benevolent type under-investing in enforcement. In the remainder of our analysis, to save on notation, we will drop the target $I_{p}^{*}$ from the definition of the conditional probabilities, as the target is the same under all three types of strategy we consider.

If mimicking is the strategy chosen, then $\gamma_{H}=1$ and $\gamma_{L}=0$, which implies that $P\left[g=p \mid I_{p}(H)\right]=$ $\mu$, i.e. the ex-post probability of the incumbent being populist is equal to the ex-ante probability. On the other hand, if under-investment is chosen, i.e. $\gamma_{H}=0$ and $\gamma_{L}=1$, then:

$$
P\left[g=p \mid I_{p}(H)\right]=\frac{\mu q}{\mu q+(1-q)(1-\mu)}
$$

Note that $\frac{\mu q}{\mu q+(1-q)(1-\mu)}>\mu$ if and only if $q>\frac{1}{2}$. In other words, under-investment can generate an upward revision of the ex-ante probability that the incumbent is a populist only if "pooling" is sufficiently costly for the benevolent incumbent (i.e. $q$ is sufficiently large). This is because the larger is $q$, the higher is the probability that by under-investing he will end up revealing his type.

We can similarly compute the voters' beliefs when $I_{p}(L)$ is observed. In this case:

$$
P\left[g=p \mid I_{p}(L)\right]=\frac{\mu(1-q)}{\mu(1-q)+\gamma_{L}(1-q)(1-\mu)+(1-\mu) q \gamma_{H}}
$$

where again, if $\gamma_{H}=0$ and $\gamma_{L}=1$, we have that $P\left[g=p \mid I_{p}(L)\right]=\mu$, whereas $\gamma_{H}=1$ and $\gamma_{L}=0$ imply that $P\left[g=p \mid I_{p}(L)\right]=\frac{\mu(1-q)}{\mu(1-q)+q(1-\mu)}$. Hence, with over-investment, the ex-post probability that the incumbent is a populist exceeds the ex-ante one if and only if $q<1 / 2$.

Given this structure of beliefs, the sequentially rational voting rule for the median voter is to retain the incumbent if and only if, having observed the actual number of migrants, he believes that the ex-post probability that the incumbent is a populist is strictly larger than the ex-ante 
probability, i.e. $P[g=p \mid I(s)]>\mu{ }^{12}$

Given the voting strategy described above, mimicking cannot be optimal for a benevolent incumbent because in this case (i.e. $\gamma_{L}=1$ ) the ex-ante and ex-post probabilities of being a populist are the same, $P\left[g=p \mid I_{p}(H)\right]=\mu$. This implies that the incumbent will not be re-elected, because the median voter always prefers to replace him with a challenger. For the same reason, if $q \geq 1 / 2$, over-investment cannot be optimal, and the same is true for under-investment if $q \leq 1 / 2$. This allows us to immediately establish the following result:

Lemma 2 Suppose that $q=1 / 2$. Then a benevolent incumbent plays sincere and admits in the first period his preferred number of migrants.

On the other hand, if $q>\frac{1}{2}$, a benevolent incumbent may find it optimal to under-invest rather than play sincere and lose elections. If the incumbent decides to under-invest, the number of migrants entering the country will be $I_{p}(H)$ if the state of the world it low, and $I_{b}^{u}(H)$ if it is high. Moreover, if the supply of migrants turns out to be low, the incumbent will be re-elected, which implies that in the second period he will choose his most preferred number of migrants $I_{b}^{\star}(L)$. On the other hand, if the state of the world is high, he will be replaced by a populist with probability $\mu$ and by a benevolent challenger with probability $1-\mu$. Suppose that the incumbent is benevolent and let $U$ (under) denote the expected payoff from under-investment. Then the incumbent's payoff can be written as:

$$
U(\text { under })=(1-q) u\left[I_{p}(H)\right]+q u\left[I_{b}^{u}(H)\right]+(1-q) u\left[I_{b}^{*}(L)\right]+q\left\{\mu u\left[I_{p}^{*}(H)\right]+(1-\mu) u\left[I_{b}^{*}(H)\right]\right\}
$$

On the other hand, choosing his most preferred policy in the first period, a benevolent incumbent will for sure be replaced by the challenger in the second period. Denoting by $U$ (sincere) the payoff obtained by playing sincere, the payoff of the incumbent becomes:

$$
\begin{aligned}
U(\text { sincere }) & =(1-q) u\left[I_{b}(L)\right]+q u\left[I_{b}(H)\right]+ \\
& +\mu\left\{q u\left[I_{p}^{*}(H)\right]+(1-q) u\left[I_{p}^{*}(L)\right]\right\}+(1-\mu)\left\{q u\left[I_{b}^{*}(H)\right]+(1-q) u\left[I_{b}^{*}(L)\right]\right\}
\end{aligned}
$$

\footnotetext{
${ }^{12}$ If $P[g=p \mid I]>\mu$, then for the median voter it is clearly not optimal to replace the incumbent with a challenger that has a lower probability of being populist. Similarly, if $P[g=p \mid I]<\mu$, for the median voter it is optimal to replace the incumbent with a challenger that has a higher probability of being populist. Finally, when $P[g=p \mid I]=\mu$ we can show that dismissing the incumbent is optimal. First, when $P[g=p \mid I]=\mu$, dismissing the incumbent is a credible punishment because the median voter is indifferent between keeping him and replacing him with somebody with the same probability of being median. Now, we can show that the punishment in fact optimal. If a benevolent incumbent plays mimicking - and thus $P[g=p \mid I]=\mu$ - this voting strategy implies that the voter will not re-elect him. As a consequence, the incumbent will be better off by just choosing his most preferred policy in the first period and lose elections, rather than choosing the policy preferred by the median and loose elections anyway. Therefore, between mimicking the populist and revealing its type, the politician prefers to reveal its type. Thus, adopting this voting rule, the median voter induces the revelation of the politician's type. As a consequence, he re-elects the populist type and dismisses the benevolent type, thereby achieving the highest possible payoff for himself.
} 
Hence, under-investment will be preferred when $U($ under $)>U($ sincere $)$. Some additional notation will be useful to characterize the under-investment equilibrium. Let $\Delta_{H}^{1} U($ under $)=$ $u\left[I_{b}^{u}(H)\right]-u\left[I_{b}(H)\right]<0$ be the first period utility loss from under-investment when the state of the world is high - i.e. the difference between the utility from under-investment and the utility that the benevolent incumbent would obtain choosing his most preferred policy. Similarly, let $\Delta_{L}^{1} U($ under $)=u\left[I_{p}(H)\right]-u\left[I_{b}(L)\right]<0$ be the first period utility loss when the state is low. Finally, $\Delta^{2} U($ under $)=u\left[I_{b}^{*}(L)\right]-u\left[I_{p}^{*}(L)\right]>0$ denotes the second period utility gain from being in power, when the state of the world is low as compared to being replaced by a populist challenger.

Under-investment is preferred to the social surplus maximizing policy if the following holds:

$$
q \Delta_{H}^{1} U(\text { under })<(1-q)\left[\mu \Delta^{2} U+\Delta_{L}^{1} U(\text { under })\right]
$$

The left hand side of the inequality is the expected utility loss from under-investment: if the state of the world is high (which happens with probability $q$ ), by under-investing, the benevolent incumbent will generate a migration level which is higher than his most preferred one and incur in the loss $\Delta_{H}^{1} U($ under $)$. The right hand side represents the "net" expected gain from underinvestment: if the state of the world is low (which happens with probability $1-q$ ), the benevolent incumbent will obtain his most preferred level of migration in the second period, but to do so he will have to sacrifice his most preferred migration choice in the first period incurring in the loss $\Delta_{L}^{1} U($ under $)$. Note also that, since by underinvesting he gains $\Delta^{2} U$ with probability $(1-q)$, whereas by playing sincere he could obtain the same gain with a lower probability $(1-q)(1-\mu)$, then the expected gain is given by $\mu(1-q) \Delta^{2} U$.

We are now ready to characterize the equilibrium of our game when $q>\frac{1}{2}$ :

Lemma 3 Suppose that $q>\frac{1}{2}$ and let $\widetilde{q}_{u}=-\frac{\mu \Delta^{2} U+\Delta_{L}^{1} U(\text { under })}{\Delta_{H}^{1} U(\text { under })}>0$. Then a benevolent incumbent under-invests if $\frac{q}{1-q}<\widetilde{q}_{u}$, whereas he chooses the social surplus maximizing policy if $\widetilde{q}_{u}<\frac{q}{1-q}$.

Proof. Under-investment is optimal if and only if

$$
\mu(1-q)\left\{u\left[I_{b}^{*}(L)\right]-u\left[I_{p}^{*}(L)\right]\right\}>-(1-q)\left\{u\left[I_{p}(H)\right]-u\left[I_{b}(L)\right]-q\left\{u\left(I_{b}^{u}(H)-u\left[I_{b}(H)\right]\right\}\right.\right.
$$

and, if $q>\frac{1}{2}$, this inequality holds provided that $\frac{q}{1-q}<\widetilde{q}_{u}$.

Similarly, if $q<\frac{1}{2}$, a benevolent incumbent may find it optimal to over-invest in enforcement. Given $\Delta_{L}^{1} U($ over $)=u\left[I_{e}^{o}(L)\right]-u\left[I_{e}(L)\right]<0, \Delta_{H}^{1} U($ over $)=u\left[I_{p}(L)\right]-u\left[I_{e}(H)\right]<0$ and $\Delta^{2}$ (over $) U=u\left[I_{b}^{*}(H)\right]-u\left[I_{p}^{*}(H)\right]>0$ we can show the following:

Lemma 4 Suppose that $q<\frac{1}{2}$ and let $\tilde{q}_{o}=-\frac{\Delta_{L}^{1} U(\text { over })}{\mu \Delta^{2}(\text { over }) U+\Delta_{H}^{1} U(\text { over })}>0$, then the following holds. If $\frac{q}{1-q} \geq \tilde{q}_{o}$ then a benevolent incumbent chooses the sincere policy. On the other hand, if $\frac{q}{1-q}<\tilde{q}_{o}, a$ benevolent incumbent over-invests in enforcement. 
Proof. For over-investment to be optimal, $U($ over $)>U($ sincere $)$. This holds if and only if

$$
\mu q\left\{u\left[I_{b}^{*}(H)\right]-u\left[I_{p}^{*}(H)\right]\right\}>-(1-q)\left\{u\left[I_{b}^{o}(L)\right]-u\left[I_{b}(L)\right]\right\}-q\left\{u\left[I_{p}(L)\right]-u\left[I_{b}(H)\right]\right\}
$$

If $\tilde{q}_{o}<\tilde{q}_{u}$, we can also immediately establish the following

Lemma 5 Suppose that $\tilde{q}_{o}<\frac{q}{1-q}<\tilde{q}_{u}$. Then under-investment will be chosen if $q>1 / 2$, whereas the sincere policy will be chosen if $q \leq 1 / 2$.

Lemma 5 tells us that - whenever $\widetilde{q}_{o}<\frac{q}{1-q}<\widetilde{q}_{u}$ - we will (at least with some probability) observe inefficiently high illegal immigration. Hence, in the remainder of the paper we will assume that lemma 6 holds and analyze which factors can explain different patterns of illegal immigration.

\section{$5.1 \quad$ Illegal immigration, information and welfare}

Using lemmata (3)-(5), we can fully characterize the political equilibrium. Remember that in the second period the equilibrium policy choice is trivial, since there are no elections and the politician knows the supply of foreign workers. Thus, he chooses the policy that maximizes his second period utility. In the first period, on the other hand, re-election concerns shape his policy choice. Since a populist incumbent always chooses his most preferred policy and is re-elected, we focus on the more interesting case where the incumbent is benevolent:

Proposition 1 Suppose that the incumbent is benevolent and that lemma 5 holds. Then, if $q>\frac{1}{2}$, there exists a pooling equilibrium with under-investment whereby, if the state of the world is low, the benevolent incumbent admits $I_{p}(H)$ migrants and is re-elected, whereas if the state of the world is high, $I_{b}^{u}(H)$ migrants are admitted and the incumbent is voted out of office. On the other hand,

if $q<\frac{1}{2}$, there exists a separating equilibrium such that $I_{b}(L)$ migrants are admitted if the state of the world is low, $I_{b}(H)$ are admitted if it is high, and the incumbent is never re-elected.

Proof. The proposition follows from lemmata (3)-(5).

The first part of the proposition establishes an inefficiency result. A benevolent incumbent, who wants to admit more migrants than the median voter, chooses a level of illegal immigration which is inefficiently high because, to achieve his goal without incurring in an electoral punishment, he strategically under-invests in enforcement letting more foreign workers enter in a concealed way. Moreover, the median voter may end up re-electing a benevolent incumbent because, given the available information, he may not be able to distinguish whether the observed number of migrants has been chosen by a populist politician in the high state of the world or by a benevolent one in the low state. 
Besides the probability of each state of the world, other factors also play an important role in determining the likelihood of an equilibrium with under-investment. In particular, from lemma 4 we know that a benevolent incumbent under-invests in enforcement whenever $\frac{q}{1-q}<\widetilde{q}_{u}$. This allows us to establish some interesting comparative statics results. We start by analyzing the effect of changes in the distribution of capital ownership. To do so, let us define $\tilde{\lambda}_{p}$ as the median voter's ownership share such that the migration levels preferred by a populist and a benevolent under the two states of the world can be ranked as follows:

$$
I_{p}^{*}(L)<I_{b}^{*}(L)=I_{p}^{*}(H)<I_{b}^{*}(H)
$$

This implies that for every $\lambda_{p}>\tilde{\lambda}_{p}$ the ranking of most preferred migration levels for the two types of politicians is $I_{p}^{*}(L)<I_{b}^{*}(L)<I_{p}^{*}(H)<I_{b}^{*}(H)$. On the other hand, for $\lambda_{p}<\tilde{\lambda}_{p}$ the ranking is $I_{p}^{*}(L)<I_{p}^{*}(H)<I_{b}^{*}(L)<I_{b}^{*}(H)$. We can then show the following:

Proposition 2 Suppose that lemma 3 holds. Then if $\lambda_{p}>\tilde{\lambda}_{p}$ an equilibrium with under-investment is more likely to arise, the lower is the share of capital $\lambda_{p}$ owned by the median voter. If instead $\lambda_{p}<\tilde{\lambda}_{p}$, then the effect of an increase in the median's ownership share of capital is ambiguous.

Proof. Under-investment is more likely to arise the larger is $\widetilde{q}_{u}=-\frac{\mu \Delta^{2} U(\text { under })+\Delta_{L}^{1} U(\text { under })}{\Delta_{H}^{1} U(\text { under })}$ and it is easy to show that if $\lambda_{p}>\tilde{\lambda}_{p}$, then $\partial \widetilde{q}_{u} / \partial \lambda_{p}<0$. Note that $\Delta_{L}^{1} U($ under $)=u\left[I_{p}(H)\right]-$ $u\left[I_{b}(L)\right]$ and if $\lambda_{p}>\tilde{\lambda}_{p}$, then the utility loss from the policy distortion increases with $\lambda_{p}$, i.e. $\partial\left(\Delta_{L}^{1} U(\right.$ under $\left.)\right) / \partial \lambda_{p}<0$. At the same time, $\partial \Delta^{2} U($ under $) / \partial \lambda_{p}<0$, whereas $\partial\left(\Delta_{H}^{1} U(\right.$ under $\left.)\right) / \partial \lambda_{p}=$ 0 . Hence, $\partial \widetilde{q}_{u} / \partial \lambda_{p}<0$. On the other hand, if $\lambda_{p}<\tilde{\lambda}_{p}$, then $\partial \Delta^{2} U / \partial \lambda_{p}<0$, and $\frac{\partial \Delta_{L}^{1}(\text { under })}{\partial \lambda_{p}}>0$ and SO $\frac{\partial \tilde{q}_{u}}{\partial \lambda_{p}} \gtreqless 0$.

The immediate consequence of proposition 2 is that, if $\lambda_{p}>\tilde{\lambda}_{p}$, then inefficiently high illegal immigration is more likely to take place when the distribution of wealth is more unequal. The reason for this result is two-fold. On the one hand, more heterogeneity implies larger gains from strategic under-investment: the further away the incumbent is from the median-type in terms of policy preferences, the more he is willing to engage in strategic under-investment to win elections and choose his most preferred policy in the second period. On the other hand, if $\lambda_{p}$ decreases, the first period utility loss from under-investment under the low state of the world also decreases, because $I_{p}(H)$ becomes closer to $I_{b}(L)$. Hence, by decreasing the loss from the policy distortion and increasing the gain from winning elections, a more unequal capital distribution raises the chances of strategic under-investment and inefficiently high illegal immigration taking place. On the other hand, if $\lambda_{p}<\tilde{\lambda}_{p}$, then the second period utility gain and the first period utility loss both decline, and therefore the result of a change in inequality becomes ambiguous.

The size of the electoral gain from under-investment is also affected by the probability distribution of the two types of incumbent. When a benevolent incumbent knows that, by loosing 
elections, he will be replaced by an opponent, who is not very likely to be a populist, he will have less incentives to "pool" by under-investing, and viceversa. Formally:

Proposition 3 Suppose that lemma 3 holds. An equilibrium with under-investment is more likely to arise the larger the ex-ante probability $\mu$ that the incumbent is a populist.

Proof. Since underinvestment arises when $\frac{q}{1-q}<\widetilde{q}_{u}$, then under-investment is more likely the larger is $\widetilde{q}_{u}$, therefore the result trivially follows from the fact that $\partial \Delta U_{2} / \partial \mu>0$.

\section{Border vs domestic enforcement}

Having analyzed the main forces inducing a benevolent politician to adopt a strategic behavior when one enforcement technology is available, we are now ready to extend our baseline model to allow the politician to choose between two different technologies. In particular, we are interested in analyzing whether an enforcement technology which is less effective might be chosen in equilibrium. To fix our ideas, the first technology - which we call domestic enforcement - can be thought of as coinciding with the type of enforcement activity we have analyzed so far. The second one available is instead less effective, in the sense that to enforce a given migration target, it requires more resources under both states of the world. Since, in the policy debate, the control of migration flows carried out at the border is often referred to as a less effective tool as compared for example to work-site inspections (Hanson 2006), we will call border enforcement the less effective technology. Naturally, our analysis applies to any other form of inefficient use of resources.

Formally, let $\eta^{B}(\hat{I}-I)$ and $\eta^{D}(\hat{I}-I)$ respectively denote the border $(B)$ and domestic $(D)$ enforcement technology, and let

$$
\eta^{B}(\hat{I}-I)>\eta^{D}(\hat{I}-I) \forall \hat{I} \in\{\underline{I}, \bar{I}\}
$$

To simplify our analysis, we make one additional assumption, i.e. that $\eta^{B}(\underline{I}-I)=\eta^{D}(\bar{I}-I)$. In other words, enforcing a given migration target in the low state of the world using the border enforcement technology is as costly as enforcing the same target using the domestic enforcement technology if the state of the world is high. Graphically, the two instruments available can be represented as in figure 3. Moving from the left to the right, the first curve $\left(\eta^{D}(\underline{I})\right)$ represents the cost of domestic enforcement under the low state of the world. The second curve $\left(\eta^{D}(\bar{I})=\eta^{B}(\underline{I})\right)$ represents both the cost of domestic enforcement if the state of the world is high, and the cost of border enforcement if the state is low. The last curve $\left(\eta^{B}(\bar{I})\right)$ displays instead the border enforcement cost under the high state of the world.

As in our previous discussion, at the beginning of the game, neither the politician nor the public observe the supply of immigrants $\hat{I}(s)$, but they know its distribution. At the end of the 


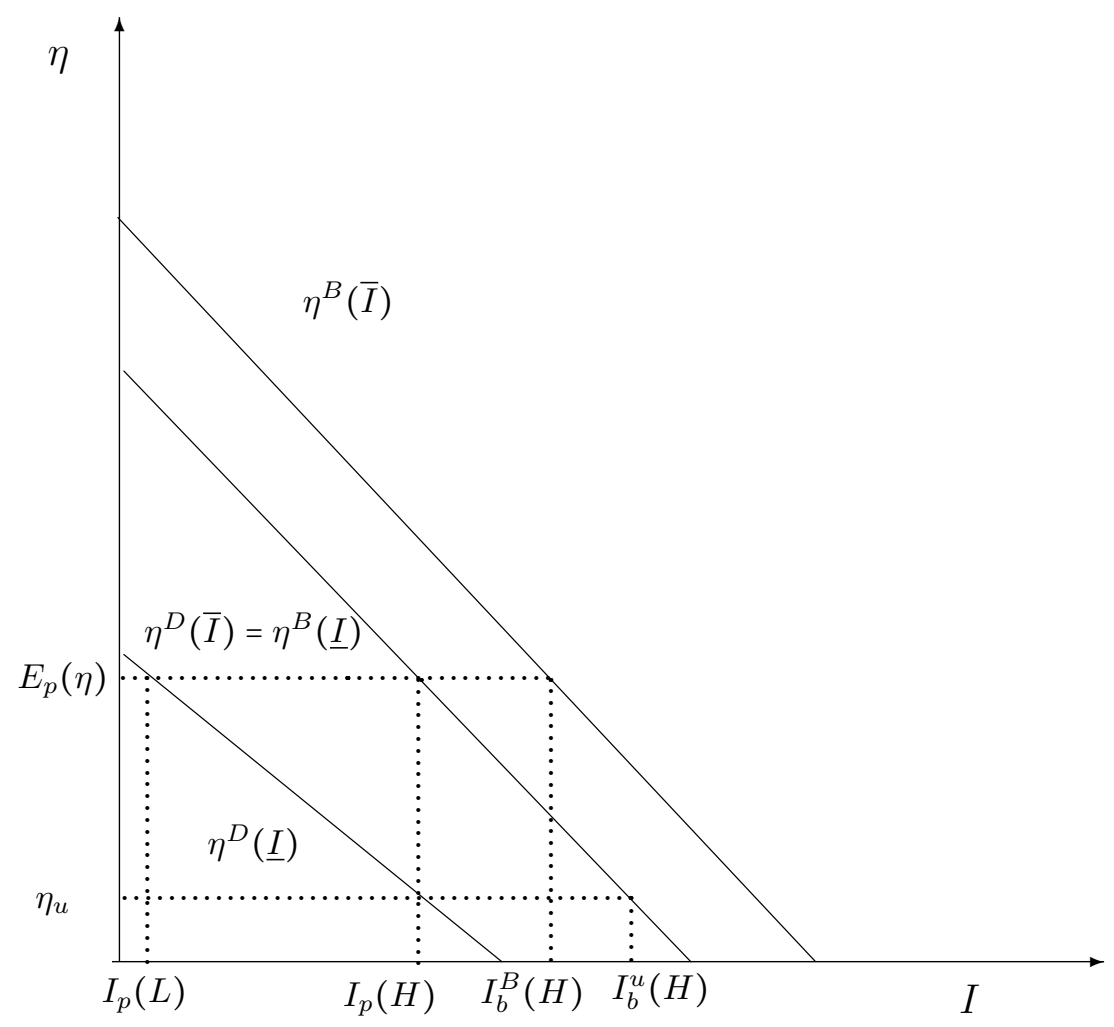

Figure 3: Illegal immigration with domestic and border enforcement 
first mandate, voters observe the number of immigrants in the country, but neither the amount of resources spent on enforcement nor how the resources have been employed (i.e. on the more or less effective technology). As a consequence, the government can now strategically set not only the budget allocated to enforcement, but also the way resources are employed. In particular, a benevolent government can admit the same number of migrants allowed by a populist when the state of the world is high, in two alternative ways. First, as before, it can strategically underinvest, spending $\eta_{U}$ and obtaining a migration level $I_{b}^{u}(L)=I_{p}(H)$ and $I_{b}^{u}(H)$ respectively if the state of the world is low and high (see figure 3). Alternatively, the benevolent politician can spend the amount of resources that would maximize the median voter's welfare $\left(E_{p}(\eta)>\eta_{U}\right)$, but employ them "ineffectively" by adopting border instead of domestic enforcement. In this case, if the state of the world is low the number of migrants admitted would be the same chosen by a populist under the high state $\left(I_{p}(H)\right)$, implying that the benevolent politician might have a chance to be re-elected. On the other hand, if the state is high, the resulting number of migrants would be $I_{b}^{B}(H)$ (see figure 3).

Given the new strategy space, we need again to describe how the median voter updates his beliefs. Let $\lambda_{D}$ and $\lambda_{B}$ denote the probability that a benevolent incumbent generates the outcome $I$ by choosing domestic $(D)$ and border $(B)$ enforcement respectively. As before, $\lambda_{L}$ denotes the probability that a benevolent incumbent generates an outcome $I$ when the state of the world is low, and $\lambda_{H}$ the probability that he generates the same outcome if the state is high. Then if voters observe the outcome $I_{p}(H)$, the ex-post probability that the incumbent is a populist can be computed as follows:

$$
P\left[g=p \mid I_{p}(H)\right]=\frac{\mu q}{\mu q+q(1-\mu) \lambda_{H}+\left[\left(\lambda_{D}+\lambda_{B}\right)(1-q)(1-\mu)\right] \lambda_{L}}
$$

where $\mu q$ is the probability that $I_{p}(H)$ is generated by a populist, $q(1-\mu) \lambda_{H}$ is the probability that it is generated by a benevolent politician mimicking the populist, and $(1-q)(1-\mu) \lambda_{L}$ is the probability that it is generated by a benevolent politician, either by under-investing in enforcement or by choosing the ineffective enforcement technology.

As before, mimicking cannot be optimal since it does not generate any positive updating in beliefs. On the other hand, whenever $q>1 / 2$, the adoption of under-investment with domestic enforcement or border enforcement generate the same positive update of beliefs. The next proposition characterizes the optimal choice of a benevolent politician if $q>1 / 2$ and both domestic and border enforcement are available. Let $u^{j}[I(s)]=\tilde{u}[I(s)]-\eta^{j}[I(s)-I]$, with $j=B, D$, where $\tilde{u}[I(s)]=\pi(E)+w(E)-c(I)$, is the component of the benevolent politician's utility function, which does not depend on the enforcement expenditure. Following the notation we have introduced in section 5 , let $\Delta_{H}^{1} U($ border $)=u\left[I_{b}^{B}(H)\right]-u\left[I_{b}(H)\right]<0$ be the first period utility loss 
from choosing border enforcement over the sincere policy when the state of the world is high, and $\Delta_{L}^{1} U$ (border $)=u\left[I_{p}(H)\right]-u\left[I_{b}(L)\right]<0$ be the first period utility loss when the state is low. $\Delta^{2} U($ border $)=u\left[I_{b}^{*}(L)\right]-u\left[I_{p}^{*}(L)\right]>0$ denotes instead the second period utility gain from being in power when the state of the world is low. Finally, let us define $\tilde{q}_{B}=-\frac{\mu \Delta^{2} U+\Delta_{L}^{1} U(\text { border })}{\Delta_{H}^{1} U(\text { border })}>0$. The following then holds:

Proposition 4 Let $q>1 / 2$ and $\frac{q}{1-q}<\tilde{q}_{u}$. Then, if $\tilde{u}\left[I_{b}^{B}(H)\right]-\tilde{u}\left[I_{b}^{u}(H)\right]<0$, the benevolent politician chooses domestic enforcement with underinvestment. If $\tilde{u}\left[I_{b}^{B}(H)\right]-\tilde{u}\left[I_{b}^{u}(H)\right]>0$, then the benevolent politician chooses border enforcement if and only if $q>\frac{E_{p}(\eta)-\eta_{U}}{\tilde{u}\left[I_{b}^{B}(H)\right]-\tilde{u}\left[I_{b}^{u}(H)\right]}$. On the other hand, whenever $\frac{q}{1-q}>\tilde{q}_{u}$, the benevolent politician chooses border enforcement if $\tilde{q}_{u}<\frac{q}{1-q}<\tilde{q}_{B}$, whereas he implements the sincere policy if $\tilde{q}_{u}<\tilde{q}_{B}<\frac{q}{1-q}$.

Proof. Note that if $\frac{q}{1-q}<\tilde{q}_{u}$, from Lemma 3 we know that underinvestment with domestic enforcement is preferred to the sincere policy. Hence, border enforcement is chosen over domestic enforcement if the resulting expected payoff is larger. This is true if and only if

$$
q\left\{\tilde{u}\left[I_{b}^{B}(H)\right]-\tilde{u}\left[I_{b}^{u}(H)\right]\right\} \geq E_{p}(\eta)-\eta_{U}
$$

Remember that $E_{p}(\eta)-\eta_{U}>0$. Hence, if $\tilde{u}\left[I_{b}^{B}(H)\right]-\tilde{u}\left[I_{b}^{u}(H)\right]<0$, then inequality 10 is never satisfied, whereas if $\tilde{u}\left[I_{b}^{B}(H)\right]-\tilde{u}\left[I_{b}^{u}(H)\right]>0$, inequality 10 is satisfied if and only if $q>\frac{E_{p}(\eta)-\eta_{U}}{\tilde{u}\left[I_{b}^{B}(H)\right]-\tilde{u}\left[I_{b}^{u}(H)\right]}$. Lemma 3 tells us also that if $\frac{q}{1-q}>\widetilde{q}_{u}$, the sincere policy is preferred to domestic enforcement. Hence, border enforcement is chosen over the sincere policy if the resulting payoff is larger, i.e. iff

$$
\mu(1-q) \Delta^{2} U(\text { border })>-q \Delta_{H}^{1} U(\text { border })-(1-q) \Delta_{L}^{1} U(\text { border })
$$

and this is true if and only if $\tilde{q}_{u}<\frac{q}{1-q}<\tilde{q}_{B}$.

The intuition for the result is as follows. The first part of proposition 4 (i.e. when $\frac{q}{1-q}<\tilde{q}_{u}$ ) highlights the conditions under which border enforcement is preferred to domestic enforcement with underinvestment. When the state of the world is low, domestic enforcement generates the same number of migrants as border enforcement, using less resources to carry out the enforcement activities, and for this reason it is preferred by the benevolent politician. On the other hand, when the state of the world is high, there is a potential gain from using the less efficient technology (border) which arises because, by spending more resources to carry out enforcement activities, the number of migrants allowed under the high state of the world may be closer to the benevolent politician's ideal number. When this happens, the utility gain from the policy net of the enforcement cost is positive (i.e. $\tilde{u}\left[I_{b}^{B}(H)\right]-\tilde{u}\left[I_{b}^{u}(H)\right]>0$ ), thus implying that the less efficient enforcement technology can be preferred. In this case, if the high state of the world is sufficiently likely (i.e. $q>\frac{E_{p}(\eta)-\eta_{U}}{\tilde{u}\left[I_{b}^{B}(H)\right]-\tilde{u}\left[I_{b}^{u}(H)\right]}$ ), the benevolent legislator prefers border to domestic 
enforcement. This is more likely to happen the larger is the utility gain (net of the enforcement cost) as compared to the difference in enforcement costs $E_{p}(\eta)-\eta_{U}$.

The second part of the proposition (i.e. when $\frac{q}{1-q}>\tilde{q}_{u}$ ) shows that, even if the sincere policy is preferred to domestic enforcement, border enforcement might still be chosen in equilibrium. In other words, allowing for an additional instrument besides underinvestment, enables the benevolent politician to sustain a pooling equilibrium in which he can generate "excessive" illegal immigration that could have not been sustained if only underinvestment was available.

In our analysis so far, voters are uninformed both on the amount of resources spent and on the effectiveness of the enforcement technology. After September 11, migration policy in the US has come under increased scrutiny, and much attention has been put on the activities of the newly established Department of Homeland Security, which has seen its budget substantially increase. As this has been widely discussed in the press and the other media, one could think that the public has become better informed concerning the resources invested in migration policy enforcement. In terms of our model, this implies that the electorate might have gained access to information on the size of the enforcement budget. How does this change our results? First note that, when the enforcement budget is known, the under-investment strategy allows the public to perfectly infer the politician's type. As a consequence, an equilibrium with domestic enforcement and underinvestment cannot arise. On the other hand, inefficiently high illegal immigration can still occur as a result of an ineffective use of the resources spent on enforcement. In particular, we can show that the following holds:

Lemma 6 Suppose that the median voter observes the amount of resources spent on enforcement. Then the benevolent politician chooses border enforcement if $\frac{q}{1-q}<\tilde{q}_{B}$, whereas he chooses the sincere policy if $\frac{q}{1-q}>\tilde{q}_{B}$.

Proof. Since the sincere strategy is always preferred to domestic enforcement, then border enforcement is chosen if and only if it delivers an higher payoff than the sincere strategy and this is true if and only if if $\frac{q}{1-q}<\tilde{q}_{B}$.

Note that, when more information becomes available to the public, domestic enforcement with under-investment cannot be used any longer by the benevolent politician to "pool" with a populist one. As a result, the benevolent politician will resort more often to the adoption of the sincere policy to admit the constrained social optimal number of migrants.

\section{Conclusions}

In this paper we have developed a model in which illegal immigration arises endogenously as the result of a binding official immigration quota and lax enforcement. We have shown that electoral 
concerns play a crucial role in explaining "excessively high" illegal immigration, resulting from the use of suboptimal policies. Motivated by the recent US experience, we have considered two sources of policy inefficiency. On the one hand, the government might strategically underfund migration control operations; on the other, it might respond to public pressure for adequate funding, but strategically use the resources in an ineffective way. We have shown that, as long as the government has an information advantage over the public concerning the way it controls migration flows, it might find it optimal to announce a target pleasing a majority of the electorate, but then strategically relax its enforcement, by either underinvesting or using resources ineffectively. Thus, our paper is able to explain both the prevailing political rhetoric of "closed" borders, and the large number of illegal immigrants brought about by a lax policy enforcement.

We can think of at least two lines along which our analysis could be extended. First, in our model undocumented immigrants do not differ in any way from legal foreign workers. In particular, we have not analyzed the working of a dual labor market, which is important to understand the economics of illegal immigration. Furthermore, we have also abstracted away from considering the interactions between immigrants and the destination country's welfare state system, which may play an important role in shaping policy preferences (Hanson, Scheve, and Slaughter 2007, Facchini and Mayda 2009). An analysis of a richer model which considers both these aspects is left for future research.

Second, the process through which immigration policy enforcement is captured in our paper is rather simple, i.e. it boils down to an enforcement cost function. In reality, the implementation of the legislated immigration policy in the United States involves the interaction of multiple government agencies both at the federal and the local level. An analysis of the micro-level interactions between the various entities taking part in the enforcement process might provide further important insights to understand some of the immigration policy puzzles we observe.

\section{References}

Alesina, A. and D. Rodrik (1994). Distributive politics and economic growth. Quarterly Journal of Economics 109, 465-490.

Banerjee, A. (1997). A theory of misgovernance. Quarterly Journal of Economics 112, 12891332.

Benhabib, J. (1996). On the political economy of immigration. European Economic Review 40, $1737-1743$.

Berry, R. A. and R. Soligo (1969). Some welfare aspects of international migration. Journal of Political Economy 77, 778-794. 
Besley, T. (2006). Principled agents? The political economy of good government. Oxford University Press.

Besley, T. and M. Smart (2007). Fiscal restraint and voter welfare. Journal of Public Economics 91, 755-773.

Bond, E. W. and T. J. Chen (1987). The welfare effects of illegal immigration. Journal of Development Economics 23, 315-328.

Borjas, G. J. (1995). The economic benefits from immigration. Journal of Economic Perspectives $9(2), 3-22$.

Briggs, V. L. (1982). Report of the Select Commission on Immigration and Refugee Policy: A critique. Texas Business Review 56, 11-15.

Calvert, R. L., M. J. Moran, and B. R. Weingast (1989). A theory of political control and agency discretion. American Journal of Political Science 33, 588-611.

Chau, N. H. (2001). Strategic amnesty and credible immigration reform. Journal of Labor Economics 19, 604-633.

Chau, N. H. (2003). Concessional amnesty and the politics of immigration reform. Economics and Politics 15, 193-224.

Coate, S. and S. Morris (1995). On the form of transfers to special interests. Journal of Political Economy 103, 1210-1235.

Cornelius, W. A., T. Takeyushi, P. L. Martin, and J. F. Hollifield (2004). Controlling Immigration: A Global Perspective. Stanford: Stanford University Press.

Diajic, S. (1987). Illegal aliens, unemployment and immigration policy. Journal of Development Economics 25, 235-249.

Dolado, J. (2007). The Spanish approach to immigration. Vox EU.

Dutt, P. and D. Mitra (2002). Endogenous trade policy through majority voting: An empirical investigation. Journal of International Economics 58, 107-134.

Epstein, G. S. and S. Nitzan (2006). The struggle over migration policy. Journal of Population Economics 19, 703-723.

Ethier, W. J. (1986). Illegal immigration: The host country problem. American Economic Review 76, 56-71.

Facchini, G. and A. M. Mayda (2009). Individual attitudes towards immigrants: Welfare-state determinants across countries. Review of Economics and Statistics 91, 295-314. 
Facchini, G. and A. M. Mayda (2010). What drives immigration policy? Evidence from a survey of government officials. In I. Gang and G. S. Epstein (Eds.), Culture and Migration, pp. forthcoming. Chicago: World Scientific.

Facchini, G. and G. Willmann (2005). The political economy of international factor mobility. Journal of International Economics 67(1), 201-219.

Fasani, F. (2009). Deporting undocumented immigrants: The role of labor demand shocks. mimeo, University College London.

Findlay, R. and S. Wellisz (1982). Endogenous tariffs, the political economy of trade restricitions and welfare. In J. Bhagwati (Ed.), Import competition and response, pp. 158-187. Chicago: University of Chicago Press.

Hanson, G. H. (2006). Illegal migration from Mexico to the United States. Journal of Economic Literature 44, 869-924.

Hanson, G. H., K. F. Scheve, and M. J. Slaughter (2007). Public finance and individual preferences over globalization strategies. Economics \& Politics 19, 1-33.

Hanson, G. H. and A. Spilimbergo (2001). Political economy, sectoral shocks, and border enforcement. Canadian Journal of Economics 34(3), 612-638.

Hillmann, A. L. and A. Weiss (1999). A theory of permissible illegal immigration. European Journal of Political Economy 15, 585-604.

Mukherjee, D. and I. Png (1995). Corruptible law enforcers: How should they be compensated. Economic Journal 105, 145-159.

Pagano, M. and G. Immordino (2010). Legal standards, enforcement, and corruption. Journal of the European Economic Association 8, 1104-1132.

Polinsky, A. M. and S. Shavell (2007). The theory of public enforcement of law. In A. M. Polinsky and S. Shavell (Eds.), Handbook of Law and Economics, Volume 1, pp. 403-454. Elsevier.

Reid, H., R. Durbin, C. Schumer, D. Feinstein, P. Leahy, and R. Menendez (2010). Real enforcement with practical answers for immigration reform (REPAIR) proposal. mimeo.

Stigler, G. J. (1970). The optimum enforcement of laws. Journal of Political Economy 78, 526536.

Weingast, B. R. and M. J. Moran (1983). Bureaucratic discretion or congressional control? Regulatory policymaking by the federal trade commission. Journal of Political Economy 91, 765-800. 
Woodland, A. D. and C. Yoshida (2006). Risk preference, immigration policy and illegal immigration. Journal of Development Economics 81, 500-513. 